\title{
Chemical characteristics of grapes cv. Syrah (Vitis vinifera L.) grown in the tropical semiarid region of Brazil (Pernambuco state): influence of rootstock and harvest season
}

\author{
Juliane Barreto de Oliveira, ${ }^{a^{*}} \odot$ Ricardo Egipto, ${ }^{\mathrm{a}, \mathrm{b}} \odot$ Olga Laureano, ${ }^{\mathrm{a}}$ Rogério \\ de Castro, ${ }^{a}$ Giuliano Elias Pereirac ${ }^{\top}$ and Jorge Manuel Ricardo-da-Silva ${ }^{a}$
}

\begin{abstract}
BACKGROUND: Obtaining two or more successive annual vintages from the same vineyard is characteristic of regions with a tropical climate, such as the Submédio of the São Francisco Valley, Brazil. The present study aimed to characterize the chemical composition of grapes in four production cycles (i.e. two calendar years) when considering the interaction between cv. Syrah and two rootstocks. For a broad characterization, two methodologies for the extraction of phenolic compounds were used, as well as different methods of analysis.

RESULTS: The results obtained showed that there was an influence of rootstock and harvest season. Grapes from vines grafted onto IAC 313 contained higher concentrations of total condensed tannins (skins) and flavanols than grapes from vines grafted onto 1103P. However, the grape samples from the vines grafted onto 1103P contained higher levels of monomeric anthocyanins than the grape samples from the vines grafted onto IAC 313. The first harvest season was characterized by higher concentrations of most phenolic compounds than the second harvest season.
\end{abstract}

CONCLUSION: In the present study, it was possible to confirm that, in the semiarid region of Brazil, the interaction between the cultivar Syrah and the different rootstocks, as well as the climatic conditions in each harvest season, influenced the composition of the grapes, mainly in relation to phenolic compounds.

(c) 2019 Society of Chemical Industry

Keywords: harvest seasons; phenolic compounds; red grapes; rootstocks; tropical semiarid viticulture

\section{INTRODUCTION}

Viticulture is a typical farming activity of temperate zones and has expanded to regions with a warm climate based on the local grapevine cultivar (Vitis vinifera L.). Technological advances in crop management have enabled grape growing in tropical regions on a commercial scale. Tropical viticulture is typical of regions where minimum temperatures are not sufficiently low to induce natural vegetative repose in the vines. The vine grows continuously and, by use of appropriate technology, it is possible to obtain two or more harvests per year in the same vineyard, ${ }^{1}$ as is typical in the region of the Submédio São Francisco Valley in Northeast Brazil.

Data from the International Grape and Wine Organization in 2016 indicate that the principal vineyards in the world occupy a total of 7516000 ha of land, with Brazil containing 85000 ha of vineyards. Brazil produced 1.1 million tons of grapes in 2016 and $33 \%$ of this production was from $V$. vinifera L. grapes, ${ }^{2}$ demonstrating the importance of Brazil in worldwide viticulture.

The composition of grapes is the result of intrinsic factors (variety, clone and rootstock), as well as extrinsic factors, such as climatic conditions, soil type, region and cropping techniques. According to Gonzalez-Neves et al., ${ }^{3}$ the genetic factors that affect the composition of grapes determine the oenological potential of each grape variety, and a large group of phenolic substances can be used to characterize different varieties of grapes.

In vineyards, rootstocks have been used since the second half of the 19th Century as a result of the accidental invasion of phylloxera (Daktulosphaira vitifoliae), which is an aphid that limits the development of cultivars of $V$. vinifera $L$. Today, besides being used as a form of resistance, rootstocks are used for other purposes: to adapt the plant to certain climatic conditions (temperate or tropical regions); to different soil types (limestone, acidic or saline); to control pests and soil diseases (nematodes and fusariosis, amongst

\footnotetext{
Correspondence to: JB de Oliveira, Linking Landscape, Environment Agriculture and Food, Instituto Superior de Agronomia, Universidade de Lisboa, Tapada da Ajuda, 1349-017 Lisbon, Portugal.

E-mail:juliane.barreto@hotmail.com

a LEAF-Linking Landscape, Environment, Agriculture and Food. Instituto Superior de Agronomia, Universidade de Lisboa, Lisbon, Portugal

b INIAV, I.P., Pólo de Dois Portos, Dois Portos, Portugal

c Brazilian Agricultural Research Corporation Embrapa Grape \& Wine, Bento Gonçalvs, Brazil
} 
others); and to control the vigor of the grapevine, influencing the development and production of grapes. ${ }^{4}$ According to Reynolds and Wardle, ${ }^{5}$ the use of a rootstock affects the size of the berry and its chemical composition such as the content of sugars, organic acids and anthocyanins, consequently influencing the composition of the wine. In most cases, it is difficult to determine whether changes in the grape composition are a direct result of the accumulation of metabolites or an indirectly result relating to differences in vigor, productivity or architecture of the canopy in the plants. $^{6}$

The use of the rootstock alters the absorption of water and minerals, and also affects the physiological process and, consequently, the vigor and yield of the vine, besides the composition in grapes. Paulsen 1103 rootstock was obtained by crossing between the species Vitis berlandieri versus Vitis riparia. This rootstock induces the formation of canopy with high vigor effect, which can delay maturation, also presents an early vegetative cycle and good adaptation to dry and clayey soils. The IAC 313 or 'Tropical' is the result of a crossing between Golia ( $V$. riparia versus $V$. vinifera L.) and Vitis cinerea, presenting the canopy with vigorous growth and good adaptation to argillaceous, arenaceous and acid soils. ${ }^{7}$

The climate influences vine physiology via temperature, rainfall, vapor pressure deficit, relative evapotranspiration, sunshine hours and wind. Bioclimatic indices are useful to account for the influence of climate on vine development and grape ripening. Vine phenology can be modelled by the sum of active temperatures (i.e. sum of each daily Celsius degree over $10^{\circ} \mathrm{C}$ ). ${ }^{8}$ The heliothermic capabilities of the grapevine under semiarid conditions allow it to undergo continuous vegetative development throughout the year, making it possible to obtain more than one harvest per year. The uniqueness of this warm climate was indicated by Tonietto and Carbonneau ${ }^{9}$ when proposing the concept of a wine-growing climate with intra-annual variability. The region contains three wine-growing classes: IS1IH +3 IF-2 (moderate drought with hot nights); IS +1 IH +3 IF-2 (moderate drought, very hot and warm nights); and IS $+2 \mathrm{IH}+3 \mathrm{IF}-2$ (intense, very hot drought and warm nights), which are characteristic of the wine-growing climate with intra-annual variability, and which correspond to the regions that, under natural climatic conditions, change wine class according to the period of the year during which the grape is produced. ${ }^{9}$

The Submédio São Francisco Valley is located in the tropical semiarid region, in the west of the state of Pernambuco and north of the state of Bahia, between the parallels $07^{\circ} 0^{\prime} 00^{\prime \prime}$ and $10^{\circ} 301^{\prime} 00^{\prime \prime}$ south latitude and between the meridians $37^{\circ} 00^{\prime} 00^{\prime \prime}$ and $41^{\circ} 00^{\prime} 00^{\prime \prime}$ west longitude, with an area of $125.755 \mathrm{~km}^{2}$, and the Valley covers the municipalities of two states in Northeast Brazil (Bahia and Pernambuco). ${ }^{10}$ Most soils have a medium natural fertility potential, and the limitations to management are related to problems of depth, stoniness, slope and water regime, which also results in a variability in the soil classes of this region. ${ }^{10}$

The region is considered as new to Brazilian and world winemaking and has been producing wine for approximately 35 years. The region is characterized by the absence of a defined winter, making it possible for a vine to produce two harvests per year. In addition, wine companies can stagger the pruning and harvesting of grapes, making it possible to harvest grapes and make wines between April and December and also avoid the rainy season between January and April. The physicochemical composition and the quality of wines can vary greatly depending on harvest date (i.e. the month in which the grape was harvested and processed) because of intra-annual climatic variations. Regional grape-growing areas are located in the states of Pernambuco and
Bahia, between parallels $8^{\circ}$ and $9^{\circ}$ south latitude, with an average altitude of $350 \mathrm{~m}$ and a tropical semiarid climate. ${ }^{9}$

The present study aimed to characterize the composition of Syrah grapes (main red variety of this region) in relation to their interaction with different rootstocks, as well as to the climatic variation in each harvest season. The work differs from previous other studies conducted in the region, mainly as a result of the detailed analysis of the phenolic composition in different parts of the grapes (skin, seed and pulp) and the period of analysis (four harvest seasons in 2 years).

\section{MATERIALS AND METHODS Vineyards localization and plant material}

The work described in the present study was carried out in experimental vineyards belonging to the Santa Maria farm, which is located in the municipality of Lagoa Grande, Pernambuco, Brazil, at latitude $8^{\circ}$ to $9^{\circ} 02^{\prime} \mathrm{S}$ and longitude $40^{\circ} 11^{\prime} \mathrm{W}$. Vineyards were planted in a vertical trellis system, with a vine spacing of $3.0 \times 1.0 \mathrm{~m}$, north-south rows orientation, and the use of drip irrigation.

The $V$. vinifera L. Syrah variety, which is considered to be the main red cultivar in the region, was used in the present study. Clone 470 was grown on two rootstocks, IAC 313 and Paulsen 1103, and the vines were approximately 10 years of age in the first year of study. The vines were located in the same area. The experimental design comprised a randomized block, with three replicates of five vines (15 vines) being randomly selected per rootstock (totaling 30 vines along of the vineyard).

Samples for the first semester of the year were collected in July (years 2016 and 2017), whereas harvesting of the grapes relative to the second semester of the year was carried out in December (2014 and 2016 years). Bioclimatic data of the region during the study are shown in Fig. 1, with data being collected daily at a weather station located on the farm.

\section{Extraction of the grape phenolic compounds}

During harvest, all bunches of grapes were collected from the 15 grapevines marked in the field. In the laboratory, berries of grapes were randomly collected at the beginning, middle and end, inside and outside of each bunch. Then, two methods of extraction of phenolic compounds were performed.

The first extraction method was proposed by Carbonneau and Champagnol, ${ }^{11}$ and the extract was obtained by macerating the skins and seeds (of 200 berries) for $24 \mathrm{~h}$ at $20^{\circ} \mathrm{C}$, using ethanol (96\%) and tartaric acid solution at pH3.2 as solvents. Then, the extract was centrifuged at $1096 \mathrm{~g}$ for $10-15 \mathrm{~min}$, before being used.

In the second extraction method, skins (35-50 g), pulp $(120-160 \mathrm{~g})$ and seeds $(7-12 \mathrm{~g})$ were separated from different bunches and berries. The phenolic compounds were extracted in accordance with the method proposed by Bourzeix et al. ${ }^{12}$ using solvents of different polarities (methanol, water and acetone) and with different contact times for consecutive maceration.

\section{Technological maturity parameters}

The grape must obtained by the method proposed by Carbonneau and Champagnol ${ }^{11}$ was lightly filtered and subjected to analysis of $\mathrm{pH}$, total soluble solids and total acidity, as well as tartaric and malic acids, using the methods proposed by the International Organization of Grape and Wine ${ }^{13}$. 


\section{(A)}

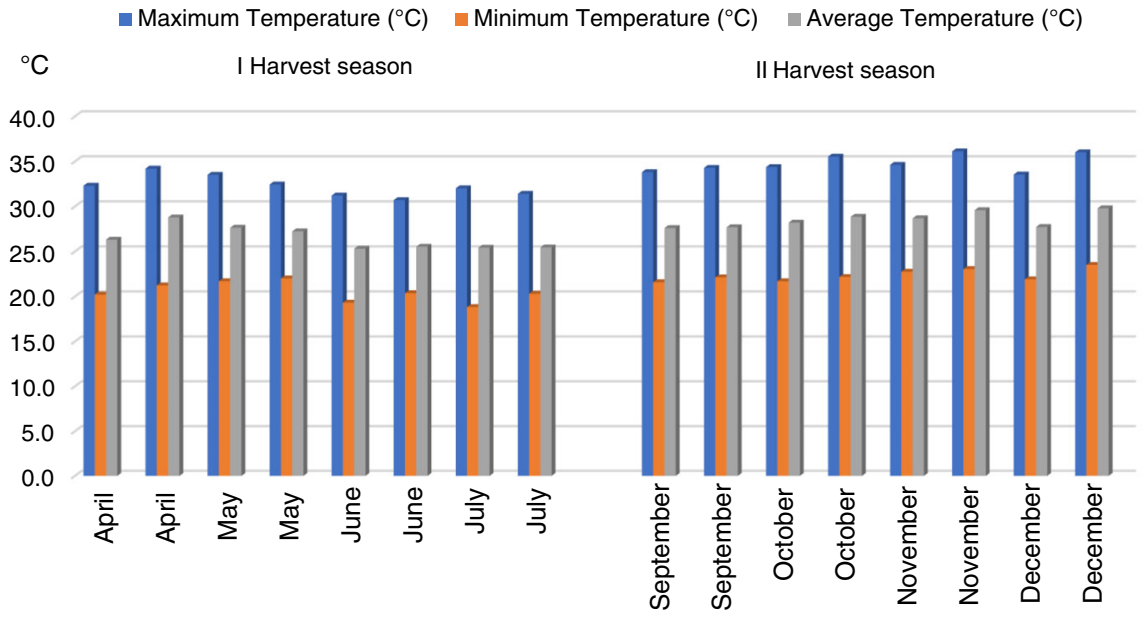

$20162017201620172016201720162017 \quad 20142016201420162014201620142016$

(B)

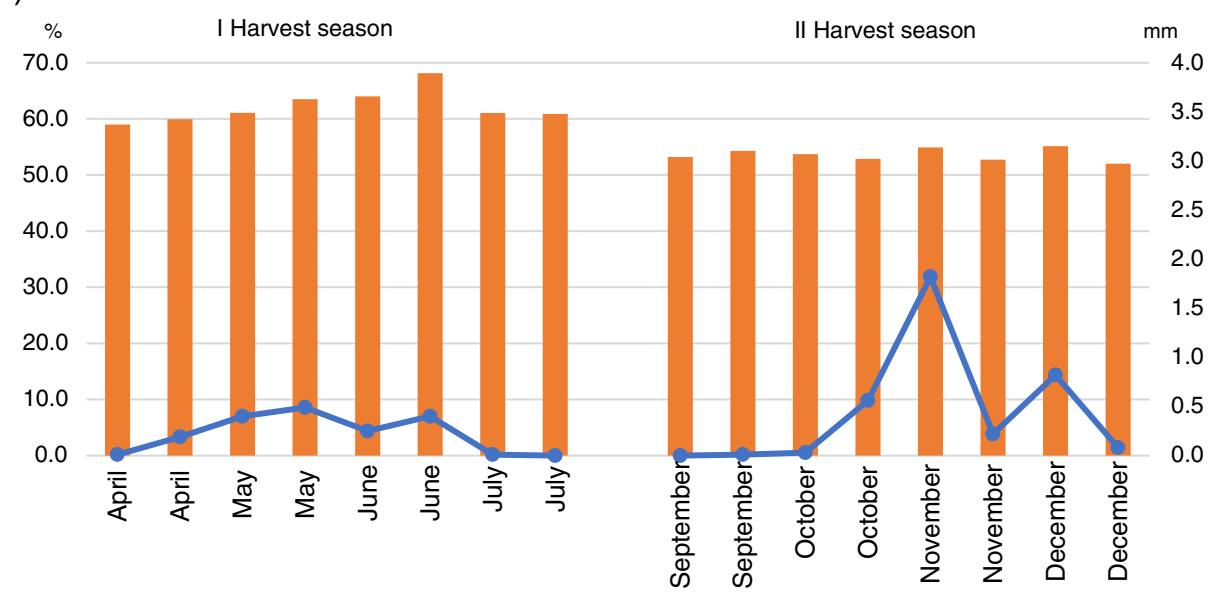

2016201720162017201620172016201720142016201420162014201620142016

Figure 1. Bioclimatic indices related to production cycles of vines in two harvest seasons and different years of study in the state of Pernambuco, tropical semiarid region in Brazil. I harvest, harvest of the first semester of the year; Il harvest, harvest of the second semester of the year; Figure $1 \mathrm{~A}$, temperatures; Figure $1 \mathrm{~B}$, relative humidity and rainfall.

Spectrophotometric analyses (i.e. of the solid part extract obtained by the method proposed by Carbonneau and Champagnol ${ }^{11}$ ) were conducted for total phenols, ${ }^{14}$ non-flavonoids and flavonoids, ${ }^{15}$ total anthocyanins, ${ }^{16}$ color intensity and tonality, ${ }^{13}$ tanning power ${ }^{17}$ and individual monomeric anthocyanins. ${ }^{18}$

The individual extracts of skins, pulps and seeds (obtained by method proposed by Bourzeix et al. ${ }^{12}$ ) were used for the fractionation of flavanols as a function of their molecular weight. ${ }^{19}$ The low molecular weight flavanols were fractionated according Ricardo-da-Silva et al. ${ }^{20}$ and the flavanols were isolated on a Fractogel chromatographic column (Merck Millipore, Burlington, MA, USA) following further degradation by acid-catalyzed depolymerization in the presence of toluene- $\alpha$-thiol, followed by high-performance liquid chromatography (HPLC) analysis. ${ }^{21-23}$

\section{Statistical analysis} performed by analysis of variance (ANOVA). Differences between each treatment were tested by a multiple means comparison test
(Tukey's honestly significant difference). $P<0.05$ was considered statistically significant. A principal component analysis (PCA) was applied to the data with respect to anthocyanins, fractionation of condensed tannins (flavanols) and small flavanols to evaluate the effects on grapes cultivated at the two altitudes. Both analyses were carried out using Statistix, version 9.0 (Analytical Software, Tallahassee, FL, USA).

\section{RESULTS AND DISCUSSION Technological maturity parameters}

Technological berry parameters are shown in Table 1 . Differences were observed for some parameters. The $\mathrm{pH}$ vales ranged from 3.68 to 3.98 for Syrah grapes of IAC 313-grafted vines and from 3.59 to 4.29 for Syrah grapes of 1103P-grafted vines, between the second and first harvest season, respectively. The $\mathrm{pH}$ values for grapes in this region are considered to be high compared to those of other traditional wine-making regions. According to Sigler, ${ }^{24}$ in warm weather (with average temperatures close to $30^{\circ} \mathrm{C}$ ), the $\mathrm{pH}$ of grapes is close to or above 4.00 , differing from the values 


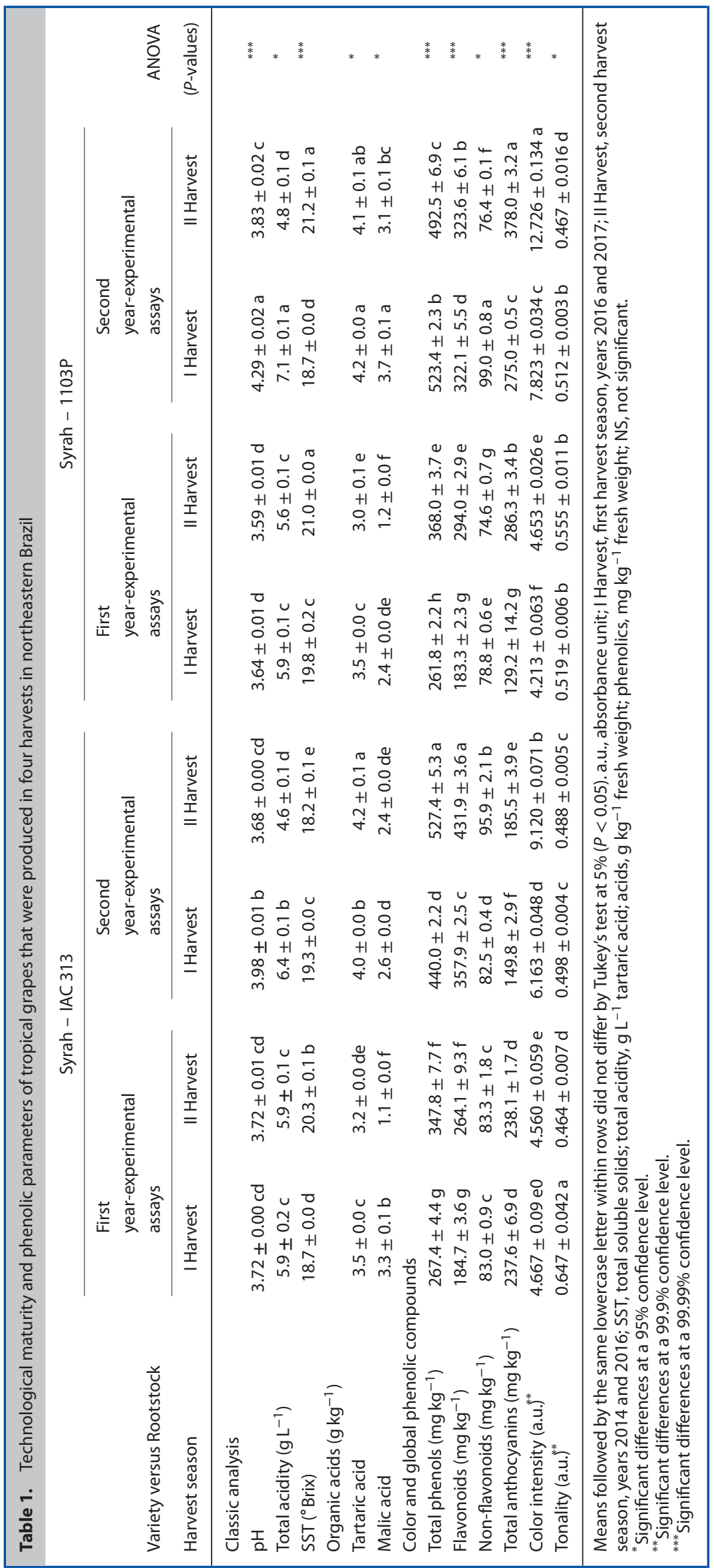


measured in other traditional wine-making regions of the world. Figure 1 shows that the average temperatures were between 25.3 and $28.8^{\circ} \mathrm{C}$ in the first productive cycle and between 27.6 and $29.8^{\circ} \mathrm{C}$ for the second productive cycle of the grapevine, which could explain the high $\mathrm{pH}$ values found in the present study. High potassium contents found in the soils of the study region 7,25 may reflect the formation of acid salts at the expense of free acids, also promoting an increase of the $\mathrm{pH}$ value in grapes.

The findings with respect to total acidity (Table 1) for berries during the first harvest season reached greater values, with $7.1 \mathrm{~g} \mathrm{~L}^{-1}$ and $6.4 \mathrm{~g} \mathrm{~L}^{-1}$ of tartaric acid, for grapes from vines grafted onto $1103 \mathrm{P}$ and IAC 313, respectively. The high acidity results for the Syrah cultivar are in agreement with those of Lima et al., ${ }^{26}$ who studied the influence of the harvest season on the analytical characteristics of Syrah grapes (concentrations of approximately $4.2 \mathrm{~g} \mathrm{~L}^{-1}$ of tartaric acid) and Leão et al., ${ }^{27}$ who studied canopy management effects on Syrah grapevines under semiarid tropical conditions (concentrations between $4.3 \mathrm{~g} \mathrm{~L}^{-1}$ and $7.3 \mathrm{~g} \mathrm{~L}^{-1}$ of tartaric acid). The highest concentrations of total acidity in grapes from the first harvest season may be related to the high concentrations of tartaric acid and mainly malic acid (Table 1). These acids are degraded slowly as a result of the lower temperatures in the first harvest season than in the second season. Figure 1 shows that, in the first productive cycle, the maximum temperatures were between 30.7 and $34.2{ }^{\circ} \mathrm{C}$, and the relative humidity of the air is higher. In the second productive cycle of the vine, the maximum temperatures varied between the study years from 33.5 to $36.1^{\circ} \mathrm{C}$, with the relative humidity being lower in this cycle.

The highest concentration of tartaric acid in grapes was $4.2 \mathrm{~g} \mathrm{~kg}^{-1}$ and there were no significant differences between the rootstocks and the harvest seasons. The synthesis of tartaric acid occurs in the early stage of berry formation and, once formed, there is generally no net loss of tartaric acid as the berries mature further; however, some initial studies have suggested that tartaric acid may be catabolized when ambient temperatures exceed $30^{\circ} \mathrm{C}^{28}$

The malic acid content was higher in the first harvest season, with values ranging from $1.1 \mathrm{~g} \mathrm{~kg}^{-1}$ (Syrah IAC 313) to $3.7 \mathrm{~g} \mathrm{~kg}^{-1}$ (Syrah 1103P), than in the second harvest season. The high maximum daily temperatures during fruit ripening in the second harvest season $\left(34.1^{\circ} \mathrm{C}\right.$ in 2014 and $35.9^{\circ} \mathrm{C}$ in 2016) may have favored the degradation of this acid. According to Moreno and Peinado, ${ }^{29}$ the decrease in malic acid is strongly influenced by the temperature because, when the weather becomes warmer, the grape cells increasingly use stored malic acid to meet their increasing energy requirements.

\section{Phenolic maturity parameters}

The results of the global phenolic composition are provided in Table 1. Total phenols and flavonoids reached high concentrations in most samples in the second harvest season. Grapes from vines grafted onto IAC 313 obtained the highest values for total phenols, with $527.4 \mathrm{mg} \mathrm{kg}^{-1}$ of fresh weight and flavonoids with $431.9 \mathrm{mg} \mathrm{kg}^{-1}$ of fresh weight. For the non-flavonoid phenolic compounds, the highest concentrations were in grapes derived from vines grafted onto $1103 \mathrm{P}$, with $99.0 \mathrm{mg} \mathrm{kg}^{-1}$ fresh weight.

There was a tendency for higher concentrations of total phenolic compounds and flavonoids in the second harvest season than in the first harvest season, which could be related to a better interaction between the cultivar and the rootstock, as well as the climatic conditions in the harvest season. The synthesis and accumulation of phenolic compounds in grape berries are also determined by genetic factors and the interaction between genotype and environment. ${ }^{30}$

Regarding total anthocyanins, the concentrations ranged from 185.5 to $238.1 \mathrm{mg} \mathrm{kg}^{-1}$ berries (Syrah IAC 313) and from 286.3 to $378.0 \mathrm{mg} \mathrm{kg}^{-1}$ berries (Syrah 1103P). The highest levels were observed in grapes of vines grafted onto Paulsen 1103, which may be related to some dehydration of the berries and possible concentration of this compound. The $1103 \mathrm{P}$ rootstock is considered to be less vigorous compared to IAC $313,{ }^{31}$ under tropical conditions, which may promote less leaf formation in the canopy, leaving the clusters more exposed to climatic conditions of the region. According to Reynolds and Wardle, ${ }^{5}$ the rootstock interferes with the chemical composition, such as the sugar content, organic acids and anthocyanins. It was also possible to observe (Table 1) a trend towards a higher concentration of anthocyanins in grapes harvested in the second harvest season (hot climate) than in grapes harvested in the first harvest season (less hot climate).

\section{Monomeric anthocyanins}

The concentrations of individual anthocyanins that were analyzed by HPLC are shown in Table 2. The monoglucosylated anthocyanins delphinidin, petunidin and malvidin were higher in the samples from vines grafted onto $1103 \mathrm{P}$, at $5.3,3.9$ and $33.6 \mathrm{mg} \mathrm{g}^{-1}$ berries, respectively, than in the samples from vines grafted onto IAC 313. The monoglucosylated cyanidin was higher in the berries of the Syrah IAC 313 treatment $\left(2.3 \mathrm{mg} \mathrm{g}^{-1}\right.$ berries) than in grapes of the Syrah 1103P treatment. Concerning the harvest season effect, there was a trend towards a higher concentration of delphinidin 3-O-glucoside, peonidin 3-O-glucoside and

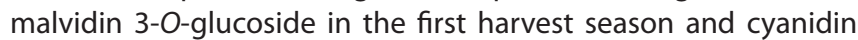
3-O-glucoside in the second season.

Regarding the anthocyanins esterified with acetic acid, the variation between the rootstocks was significant. The Syrah berries grafted onto the $1103 \mathrm{P}$ rootstock had a high content of the anthocyanin peonidin 3-O-acetylglucoside in the two harvests, with values of $1.4 \mathrm{mg} \mathrm{g}^{-1}$ and $1.8 \mathrm{mg} \mathrm{g}^{-1}$ for the first and second harvest seasons, respectively. Petunidin 3-O-acetylglucoside obtained high concentrations in the berries of vines grafted onto $1103 \mathrm{P}$ during the first harvest season $\left(5.4 \mathrm{mg} \mathrm{g}^{-1}\right.$ berries). The delphinidin 3-O-acetylglucoside concentrations were higher for grapes from vines grafted onto the Paulsen 1103 rootstock, with values of $1.3 \mathrm{mg} \mathrm{g}^{-1}$ and $1.4 \mathrm{mg} \mathrm{g}^{-1}$ berries, for the first and second harvest seasons, respectively, than for grapes from vines grafted onto the IAC 313 rootstock. In relation to the contents of malvidin 3-O-acetylglucoside, the highest concentration was in berries from vines grafted onto IAC 313 (17.0 $\mathrm{mg} \mathrm{g}^{-1}$ berries) in the second harvest season. There was a tendency for higher concentrations of the acetylglucosylated anthocyanins petunidin and delphinidin in the first harvest season of year and peonidin and malvidin in the second harvest season.

Anthocyanins that were esterified with $p$-coumaric acid were affected by harvest seasons and rootstock factors (Table 2). Syrah grapes grafted onto IAC 313 contained higher levels of petunidin in both harvests, with concentrations of $1.3 \mathrm{mg} \mathrm{g}^{-1}$ for grapes harvested in the first season and $1.6 \mathrm{mg} \mathrm{g}^{-1}$ for grapes in the second harvest season of the year, than Syrah grapes grafted onto 1103P. High delphinidin values were found in Syrah (1103P) grapes $\left(15.9 \mathrm{mg} \mathrm{g}^{-1}\right)$ in the first harvest season of the year. The concentration of delphinidin was the highest among the concentrations of the anthocyanins esterified with $p$-coumaric acid. The grapes harvested in the first harvest season contained higher concentrations of malvidin esterified with $p$-coumaric acid, with $7.1 \mathrm{mg} \mathrm{g}^{-1}$ 


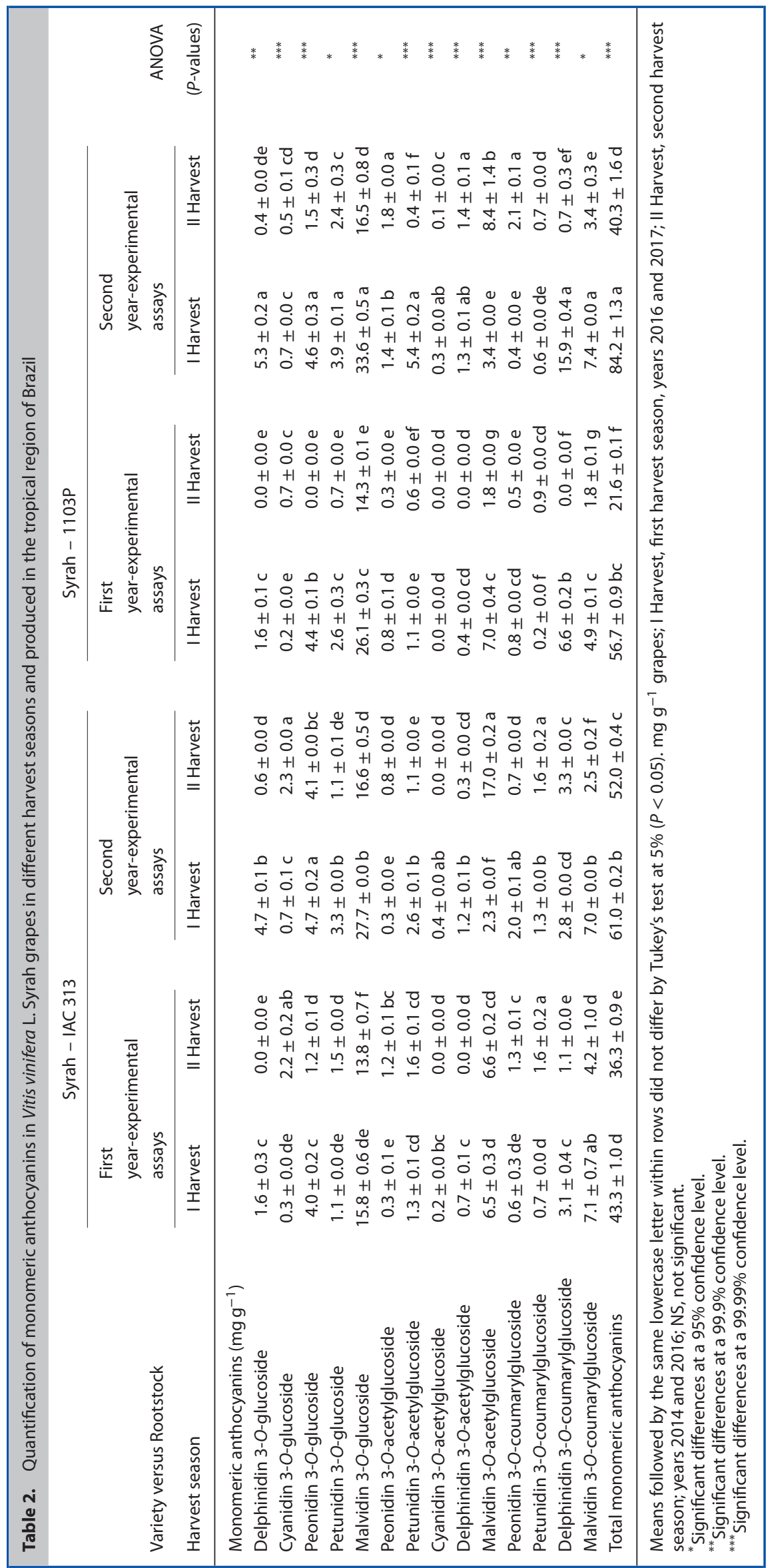


berries (IAC 313) and $7.4 \mathrm{mg} \mathrm{g}^{-1}$ berries (1103P), than the grapes harvested in the second season.

The cyanidin derivatives were one of the individual anthocyanin groups with the lowest concentrations (cyanidin 3-O-glucoside and cyanidin 3-O-acetylglucoside), which is in agreement with the results published by Costa et al. ${ }^{31}$ At the beginning of maturation, the concentrations of peonidin 3-O-glucoside and cyanidin 3-O-glucoside in the skin of the berry are higher than those of the other anthocyanins. The reduction in these compounds during maturation is most likely linked to a block in the biosynthetic pathway of anthocyanins and an increase in the synthesis of trisubstituted anthocyanins as a result of different enzymatic activities. ${ }^{32}$

The concentrations of total monomeric anthocyanins varied in grapes from grafted vines in IAC 313, ranging from 43.3 to $61.0 \mathrm{mg} \mathrm{g}^{-1}$ in the first harvest season and from 36.3 to $52.0 \mathrm{mg} \mathrm{g}^{-1}$ in the second harvest season. The concentrations of total monomeric anthocyanins in grapes from vines grafted onto Paulsen 1103 ranged from 56.7 to $84.2 \mathrm{mg} \mathrm{g}^{-1}$ berries and from 21.6 to $40.3 \mathrm{mg} \mathrm{g}^{-1}$ berries in the first and second harvest season, respectively. The results showed that the harvest season had a greater effect than of the variety and rootstock interaction, with the highest concentrations of total monomeric anthocyanins occurring in the berries of the first harvest season of the year. This result could be related to the high temperatures in the region during the productive cycles of the grapes in the second harvest season of the year (Fig. 1). High temperatures can affect the synthesis and/or degrade anthocyanins. ${ }^{8}$

As observed in the present study, the composition and concentration of anthocyanins in the berries varied between the rootstocks and harvest seasons throughout the year. According to the literature, the anthocyanidin composition of grapes is considered to be affected by several factors, such as the origin and type of the vine, degree of maturity and climatic conditions, especially light intensity and temperature. ${ }^{32}$ The anthocyanin profiles for each grape variety are relatively stable, whereas the absolute concentrations may vary widely between different harvests because of environmental and agronomic factors. ${ }^{33}$

\section{Condensed tannins in seeds, skins and pulp}

The statistical results of the concentrations of monomeric, oligomeric and polymeric tannins in seeds are shown in Table 3. The oligomeric tannins were higher in Syrah seeds from vines grafted onto Paulsen 1103 than in Syrah seeds grafted onto IAC 313 in both the first and second harvest seasons of the year, with values of $12.1 \mathrm{mg} \mathrm{g}^{-1}$ and $7.5 \mathrm{mg} \mathrm{g}^{-1}$, respectively. In relation to polymeric tannins, higher concentrations were also observed in the Syrah samples grown on the $1103 \mathrm{P}$ rootstock, with a value of $34.6 \mathrm{mg} \mathrm{g}^{-1}$.

Thus, in the present study, the seeds of Syrah grafted onto $1103 \mathrm{P}$ had higher values of total condensed tannins than the seeds of Syrah grafted onto IAC 313, demonstrating that the tannin profile in seeds may be related to variety and rootstock interaction, whereas the concentrations may be linked to the climatic conditions of the region. The lower total tannin content in skins compared to that in seeds may be a result of the stable bonds between tannins and other cellular components, such as cell wall polysaccharides, lignins and proteins, as has been reported for Syrah. ${ }^{34}$

The concentrations of condensed tannins in skins of Syrah grapes grown under tropical conditions are presented in Table 3. The oligomeric tannins in skins were higher in the Syrah (1103P) samples, with a value of $0.8 \mathrm{mg} \mathrm{g}^{-1}$ skin, in the first harvest season of the year compered to the other samples. Regarding the polymeric tannins in skins, the highest content was in the Syrah (IAC 313) sample from the second harvest season, with a value of $3.5 \mathrm{mg} \mathrm{g}^{-1}$ skin.

In the present study, small amounts of condensed tannins were detected in the pulp of the grape samples and may be related to contamination during the process of separating the pulp from the skins.

The data concerning the mean degree of polymerization (mDP), as well as percentages of galloylation and prodelphinidins in seeds and skins, are shown in Table 3 . In the analyzed seeds, the highest values for mDP were for the Syrah seeds of grapes grafted onto Paulsen 1103, with a value of 16 for the grapes of the first harvest season of 2017. These values are higher than those reported by Cosme et al. ${ }^{35}$ for Syrah grape seed extract, which was obtained under traditional viticulture conditions, with an mDP of 7.8 being observed for the variety mentioned. The percentage of galloylation $(\% \mathrm{~g})$ varied in the first harvest season of the year from $26.4 \%$ to $33 \%$ in seeds of Syrah (IAC 313) and from $25.8 \%$ to $39.2 \%$ in seeds of Syrah (Paulsen 1103). In second harvest, the values were from $29.7 \%$ to $31.5 \%$ in seeds of Syrah (IAC 313) and from $27.3 \%$ to $31 \%$ in seeds of Syrah (rootstock 1103P). A greater variation was observed between the harvests than between the rootstocks, and the greater values in the first harvest season were caused by the lower temperatures in the first harvest season than in the second.

The mDP in skins ranged from 21.7 (Syrah 1103P) to 33.4 (Syrah IAC313) in the first harvest season of the year. In the second harvest season, the values ranged from 15.1 to 40.9 for Syrah IAC 313 and Syrah 1103 , respectively. The mDP values of the present study are in agreement with the values cited in the literature, with some studies reporting mDP grades ranging from 11 to 83 , depending on the technique of fractionation employed, grape variety and vintage. ${ }^{22,36}$

Generally, the skins of the grapes are characterized by a higher percentage of prodelphinidins and lower percentage galloylation. The percentage of prodelphinidins varied from $6.5 \%$ to $9.5 \%$ in Syrah IAC 313 grapes and from $6.4 \%$ to $17.3 \%$ in Syrah grapes of the rootstock Paulsen 1103. The percentage of prodelphinidins in the present study is lower than that reported by Bordiga et al. ${ }^{37}$ in Italy in skins of the Cabernet Sauvignon variety but similar to the percentages found by Monagas et $a l^{23}$ when evaluating the Tempranillo and Graciano varieties.

In relation to the percentage of galloylation, the values in seeds were higher than those in skins. The values ranged from $26.4 \%$ (Syrah IAC 313) to 39.2\% (Syrah 1103P) in the first harvest season of the year. The percentage of galloylation in the present study is higher than that reported in other studies for other $V$. vinifera $L$. varieties, which may be related to environmental factors (terroir). Cosme et al., ${ }^{35}$ evaluating the varieties Touriga Nacional, Cabernet Sauvignon and Castelão, found values of 3.6, 4.3 and 4.3\%, respectively. Bordiga et al., ${ }^{37}$ studying tannins during the maturation of Cabernet Sauvignon skins, found $1.2 \%$ galloylation at harvest. Kyraleou et al., ${ }^{38}$ evaluating the skins of the Syrah variety during maturation, found that the percentage of galloylation ranged from $4.23 \%$ to $9.51 \%$ in the oligomeric fraction and from $0.13 \%$ to $0.42 \%$ in the polymeric fraction.

\section{Monomeric and small oligomeric flavanols in seeds}

Table 4 shows the results of the statistical analysis of the concentrations of small flavanols in seeds of Syrah grapes under tropical 


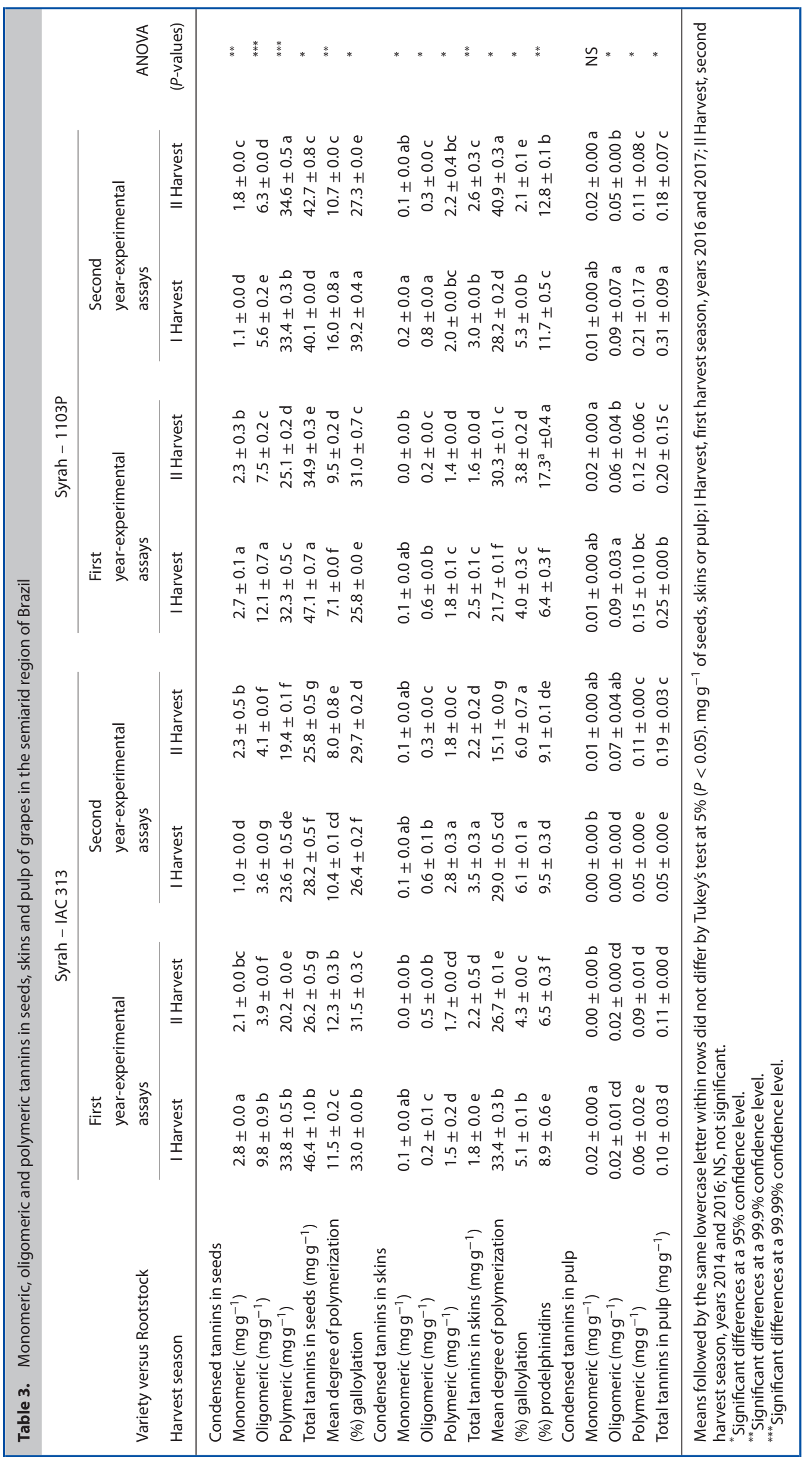




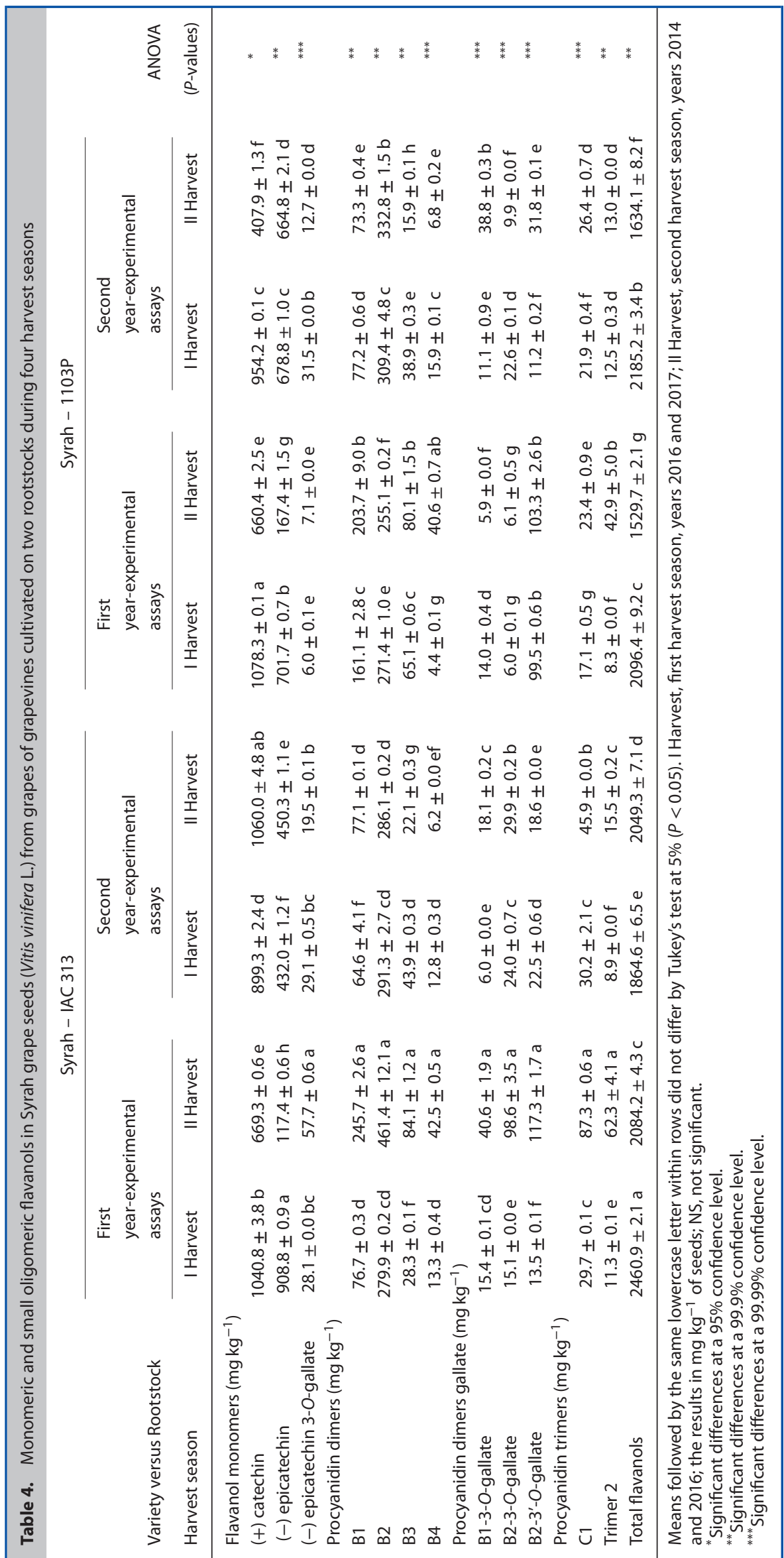


conditions. The samples of Syrah seeds of grapes grafted onto IAC 313 showed high concentrations of most identified flavanols: epicatechin $\left(908.8 \mathrm{mg}^{-1} \mathrm{~kg}^{-1}\right)$, epicatechin 3 -O-gallate $\left(57.7 \mathrm{mg} \mathrm{kg}^{-1}\right)$, B1 (245.7 $\left.\mathrm{mg} \mathrm{kg}^{-1}\right)$, B2 (461.4 $\left.\mathrm{mg} \mathrm{kg}^{-1}\right)$, B3 $\left(84.1 \mathrm{mg} \mathrm{kg}^{-1}\right)$, B4 (42.5 mg kg-1), B1-3-O-gallate $\left(40.6 \mathrm{mg} \mathrm{kg}^{-1}\right)$, B2-3-O-gallate (117.3 $\left.\mathrm{mg} \mathrm{kg}^{-1}\right)$, B2-3'-O-gallate $\left(117.3 \mathrm{mg} \mathrm{kg}^{-1}\right), \mathrm{C} 1\left(87.3 \mathrm{mg} \mathrm{kg}^{-1}\right)$ and T2 $\left(62.3 \mathrm{mg} \mathrm{kg}^{-1}\right)$. Syrah seeds of grapes grafted onto Paulsen 1103 contained only high levels of catechin $\left(1078.3 \mathrm{mg} \mathrm{kg}^{-1}\right.$ berries).

For the dimers, the seeds of grapes harvested in the second period contained higher levels than those harvested in the first period. There was a trend for a higher concentration of condensed tannins in the early stages of berry development than in the later stages of berry development, which may be related to the metabolization of tannins during maturation. The presence of a high amount of tannins in the second harvest of the year may be related to the high temperatures and low thermal amplitude during the production period, which reduce the maturation period of the grape and cause a delay between technological and phenolic maturation.

When observing the two harvests, it was possible to confirm that, in the majority of the samples, there were high total concentrations of the quantified compounds in seeds of grapes of the first harvest season, which had an average temperature of approximately $27^{\circ} \mathrm{C}$ during the maturation period. Some studies have shown a positive association between temperature and the number of seeds, as well as the total proanthocyanidins levels per berry at harvest. ${ }^{39}$

\section{Monomeric and small oligomeric flavanols in skins}

The concentrations of flavanols phenolic compounds from grape skins are shown in Table 5. A variation in the contents was observed between rootstocks. The extracts from Syrah (1103P) grapes skins contained higher concentrations of catechin (41.2 $\left.\mathrm{mg} \mathrm{kg}^{-1}\right)$, epicatechin (82.6 $\left.\mathrm{mg} \mathrm{kg}^{-1}\right), \mathrm{B} 3$ dimer $\left(9.7 \mathrm{mg} \mathrm{kg}^{-1}\right)$, B2-3-O-gallate $\left(5.3 \mathrm{mg} \mathrm{kg}^{-1}\right)$ and trimer $2\left(3.1 \mathrm{mg} \mathrm{kg}^{-1}\right)$ than the extracts from Syrah (IAC 313) grape skins.

The extracts from the grape skins from vines grafted onto IAC 313 contained higher concentrations of epicatechin 3-O-gallate (3.6 mg kg-1), dimer B1 $\left(10.2 \mathrm{mg} \mathrm{kg}^{-1}\right)$, B2 $\left(123.3 \mathrm{mg} \mathrm{kg}^{-1}\right)$, B4 (6.3 $\left.\mathrm{mg} \mathrm{kg}^{-1}\right), \quad$ B1-3-O-gallate $\quad\left(13.4 \mathrm{mg} \mathrm{kg}^{-1}\right), \quad$ B2-3'-O-gallate (4.6 $\left.\mathrm{mg} \mathrm{kg}^{-1}\right)$ and $\mathrm{C} 1\left(6.9 \mathrm{mg} \mathrm{kg}^{-1}\right)$ than the extracts from the grape skins from vines grafted onto 1103P.

The high concentrations of these compounds in the skin of Syrah grapes (IAC 313) may be related to the greater vigor of this rootstock compared to that of $1103 \mathrm{P}^{31}$ in the tropical climate condition of the study, which provides greater coverage of the canopy and protection of the grape clusters from the solar radiation and high temperatures. According to some studies, shading reduces the relative content of procyanidins in grapes grown under traditional conditions. ${ }^{37,38}$

Tables 4 and 5 show that the values of flavanols in seeds were higher than those in skins in all samples and harvesting periods. Proanthocyanidins are more sensitive to environmental factors in skins than in seeds; sunlight has been shown to affect the relative content of proanthocyanidins. ${ }^{38}$ High temperatures in the region may have influenced the degradation of these compounds in grape skins (Fig. 1).

\section{Discrimination of the samples by PCA}

Figure 2 shows discrimination among berry samples of Syrah grapes cultivated from four vintages and two different rootstocks.
Results are based on monomeric anthocyanins analyzes carried out by HPLC (Table 2), in addition to total phenols, flavonoids and non-flavonoids, analyzed by spectrophotometry (Table 1). The first two principal components explained $64.74 \%$ of total variability (PC1 versus PC2), where PC1 was responsible for $49.78 \%$ and PC2 explained $14.96 \%$. The main factor explaining grape variability was the intra-annual climate variability in the first PC, followed by rootstock effect in the second PC. PC1 separated some berry samples harvested in the first semester (less hot climate) in the positive quadrants, where there are samples of Syrah grapes from 313 rootstock in 2017_I and also Syrah grapes from 1103 rootstock in 2017_l, explained by the compounds delphinidin-glucoside, petunidin-glucoside, malvidin-glucoside, cyanidin and peonidin (acetyl-glucoside), besides delphinidin and malvidin (esterified with the $p$-coumaric acid). In the negative quadrants of PC1, there are berry samples harvested in the second semester of the year in the São Francisco Valley (hot climate), with samples of Syrah grapes from 1103 rootstock in 2016 II, also influencing PC1(-) Syrah grapes from 313 rootstock II 2014, characterized mainly by total anthocyanins. PC2 separated berry samples mainly as a result of the rootstock effect, where, in the positive quadrants, there are berries harvested in the second semester with Syrah grapes from 313 rootstock in $2016 \mathrm{Il}$, characterized by the compounds cyanidin-glucoside, petunidin ( $p$-coumaryl-glucoside) and malvidin (acetyl-glucoside). In the negative quadrants of PC2, there are not only samples of Syrah grapes from 1103 rootstock in 2016 I and Syrah grapes from 1103 rootstock in 2014 II, but also Syrah grapes from 313 rootstock in $2016 \mathrm{I}$, explained negatively by the compounds cited above in the positive quadrants, as well as by total anthocyanins (analyzed by spectrophotometry).

Figure 3 shows discrimination among berry samples from Syrah grapes cultivated from four vintages and two different rootstocks. The results are based on fractionation of condensed tannins and small oligomeric flavanols extracted from skins and seeds, analyzed by HPLC, as shown in Tables 3 and 4. The first two principal components explained $66.80 \%$ of total variability (PC1 versus PC2), where PC1 was responsible for $47.34 \%$ and PC2 explained $19.46 \%$. As for anthocyanins, the main factor explaining grape variability was the intra-annual climate variability in the first PC, followed by rootstock effect in the second PC. PC1 separated berry samples harvested in the second semester (hot climate) in the positive quadrants, where there are samples of Syrah berries from 313 rootstock II 2014, explained by the compounds monomeric flavanols in seeds, as well as dimers B3 and B2-3'-O-gallate in skins. In the negative quadrants of $P C 1$, there are berry samples harvested in the first semester of the year in the São Francisco Valley (less hot climate) with samples of Syrah grapes from 1103 rootstock in $2016 \mathrm{I}$ and from 313 rootstock in $2016 \mathrm{I}$, characterized by the compounds oligomeric and polymeric tannins, total tannin condensed in seeds, and dimer B4 in skins. PC2 separated berry samples mainly as a result of the rootstock effect, although less strongly for tannins from skins and seeds, compared to monomeric anthocyanins from skins, in the previous PCA (Fig. 2). In only one vintage was it possible to find differences. In the positive quadrants of $P C 2$, there are Syrah samples from 1103 rootstock II 2014, explained by the compounds B2-3-O-gallate in skins and monomeric flavanols in seeds, whereas, in the negative quadrants of the $y$-axis, there are samples of Syrah berries from 1103 rootstock in 2017 I and 313 rootstock in 2017 I, characterized by the compounds oligomeric tannins and total condensed tannins in skins. In this PCA, it can be observed that, in three vintages, samples from two rootstocks were less discriminated by fractionation of condensed 


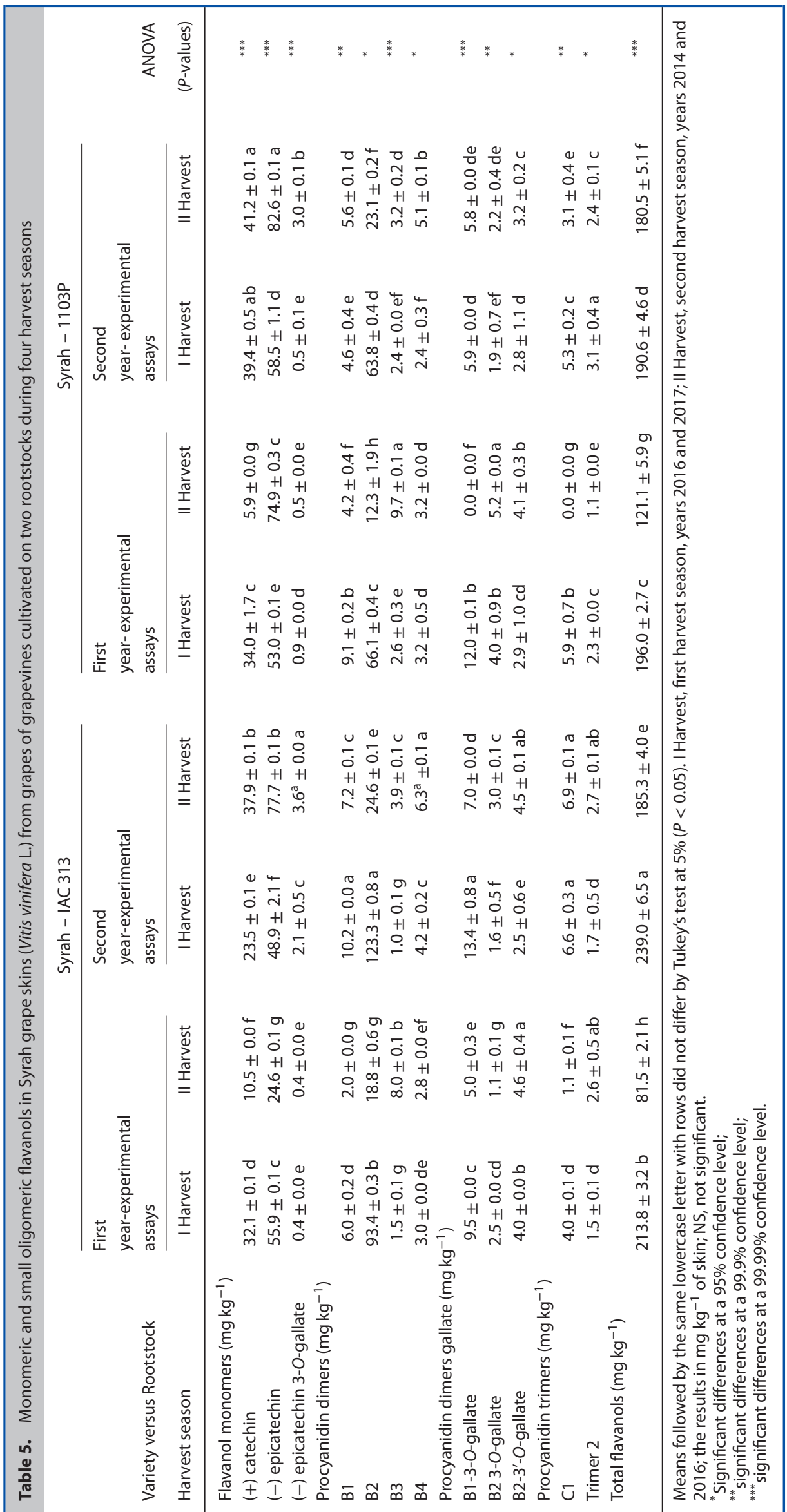


(A) Projection of the cases on the factor-plane $\left(\begin{array}{ll}1 \times & 2\end{array}\right)$ Cases with sum of cosine square $>=0,00$

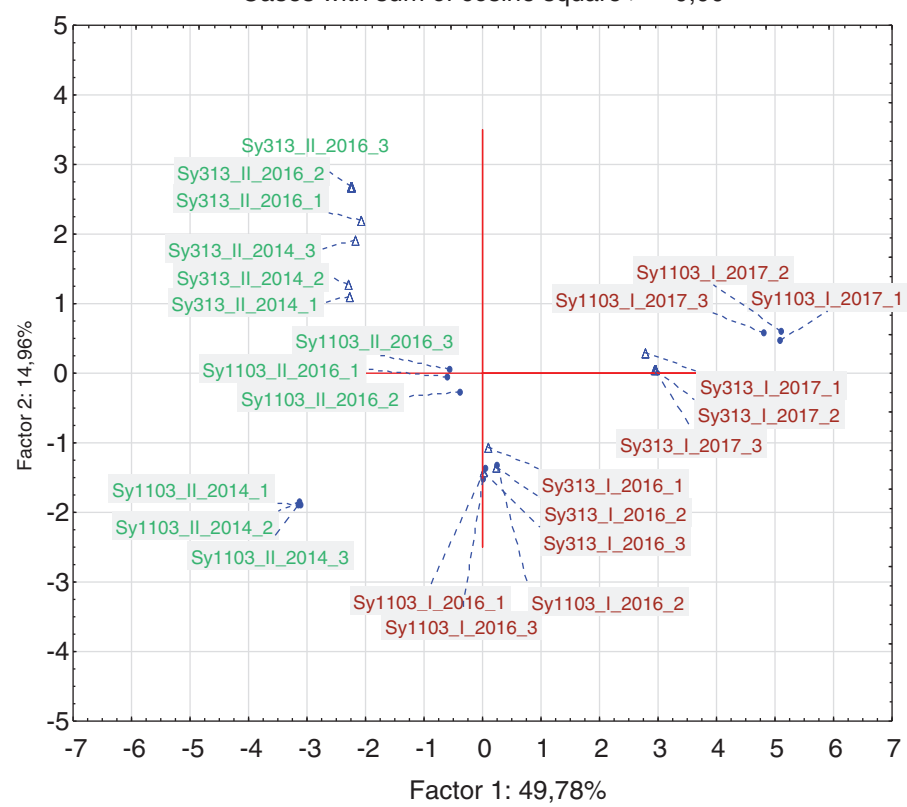

(B) Projection of the variables on the factor-plane $\left(\begin{array}{ll}1 \mathrm{x} & 2\end{array}\right)$ Active and Supplementary variables *Supplementary variable

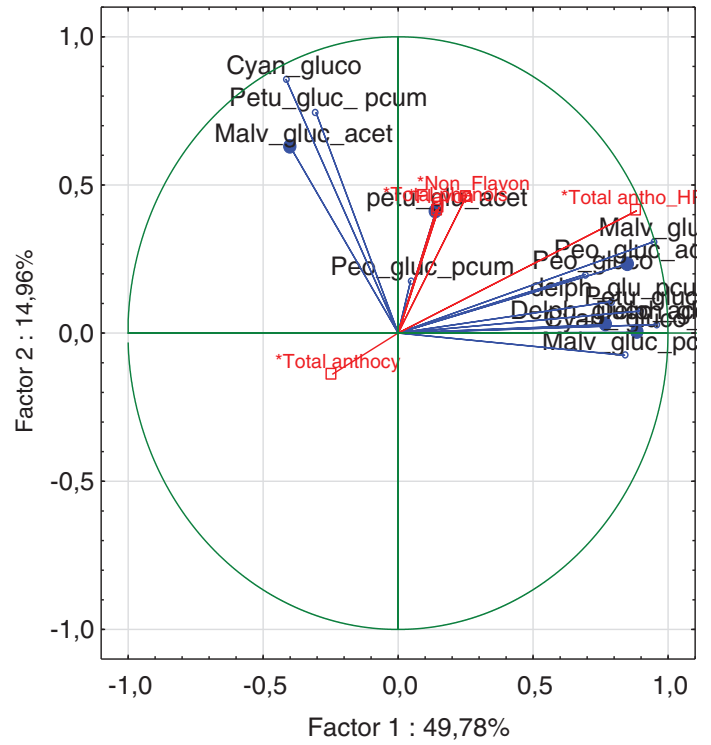

Figure 2. Principal component analysis of the individual monomeric anthocyanins, total phenols, flavonoids and non-flavonoids in Syrah (Vitis vinifera L.) grapes grown on two rootstocks and four harvest seasons in a tropical semiarid region of Brazil. All data are expressed as the average values of 3 replicates \pm standard deviation. Figure 2A, samples: Syrah 313_l, grapes from plants grafted onto IAC 313 during the first semester in the years of 2016 and 2017; Syrah 313_II, grapes from plants grafted onto IAC 313 during the second semester, in the years of 2014 and 2016; Syrah 1103_I, grapes from grapes of plants grafted onto 1103P during the first semester of 2016 and 2017; Syrah 1103_II, grapes from plants grafted onto 1103P during the second semester in the years of 2014 and 2016. Figure 2B, compounds: Delph_gluc, delphinidin 3-O-glucoside; Cyan_gluc, cyanidin 3-O-glucoside; Petu_gluc, petunidin 3-O-glucoside; Peo_gluc, peonidin 3-O-glucoside; Malv_gluc, malvidin 3-O-glucoside; Delph_gluc_acet, delphinidin 3-O-acetylglucoside;Cyan_gluc_acet, cyanidin 3-O-acetylglucoside; Petu_gluc_acet, petunidin 3-O-acetylglucoside; Peo_gluc_acet, peonidin 3-O-acetylglucoside; Malv_gluc_acet, malvidin 3-O-acetylglucoside; Delph_gluc_pcum, delphinidin 3-O-coumarylglucoside; Cyan_gluc_pcum, cyanidin 3-O-coumarylglucoside; Petu_gluc_pcum, petunidin 3-O-coumarylglucoside; Peo_gluc_pcum, peonidin 3-O-coumarylglucoside; Malv_gluc_pcum, malvidin 3-O-coumarylglucoside; Flavon, flavonoids; Non-flavon, non-flavonoids; Total anthocy, total anthocyanins; Total anthoc HPLC, total monomeric anthocyanins.

tannins and small oligomeric flavanols, as shown for 2017 I, 2016 I and 2016 II, with samples close together in the PCA, and only for 2014 II grape samples were tannins able to show differences and separation of two rootstocks. In the negative quadrant (PC1) and in the positive quadrant (PC2), it is possible to confirm a proximity between grape samples grapes grafted on IAC 313 and 1103P in the two harvest dates of the year 2016, demonstrating similarity for some compounds (oligomeric and polymeric tannins in seeds; total condensed tannins in seeds; and dimers B4 and B2 3-O_galate in skins) and this is related to small climatic differences (temperatures and rainfall) (Fig. 1) between the two times of harvest in the year 2016.

Accordingly, the present study highlights that the vintage effect, specifically two different climates in the year in the São Francisco Valley, mostly influences the monomeric anthocyanin composition of the skins, and then tannins and flavonols from skins and seeds. These findings can be confirmed by studies showing a high dependence of anthocyanins compared to tannins. ${ }^{25,39-41}$

\section{CONCLUSIONS}

In the present study, it was possible to confirm that, in the tropical semiarid climate of Brazil, the interaction between the cultivar Syrah and two rootstocks, as well as the climatic conditions in each harvest season, influenced the grape composition, mainly for phenolic compounds.

Harvest season and rootstock influenced $\mathrm{pH}$, total acidity, total soluble solids ( ${ }^{\circ}$ Brix), tartaric acid and malic acid in grapes.
Grapes from vines grafted onto IAC 313 presented higher concentrations of polymeric tannins and total condensed tannins in skins and higher contents of flavanols in seeds and skins than grapes from vines grafted onto 1103P. However, the samples of grapes from vines grafted onto 1103P presented higher levels of monomeric anthocyanins, as well as oligomeric and polymeric tannins, in seeds, and a higher mean degree of polymerization in seeds and skins.

Regarding the harvesting effect, there were variations in the samples for some phenolic compounds, especially for the grapes harvested in July of the first harvest season, which was characterized by lower temperatures and the production of grapes with higher malic acid, total monomeric anthocyanins, condensed tannins in seeds and total flavanols in skins than grapes harvested in December from the second harvest season, characterized by warmer temperatures, with different enological potentials, to be used for aging or young reds, or sparkling wines.

In general, grapes harvested in July presented higher total acidity, malic acid, total monomeric anthocyanins, total tannins in seeds and total flavonols, as well as lower total phenols, total flavonoids and total anthocyanins, than grapes harvested in December. This suggests different methods of winemaking for producers and wineries. According to the results, aging red wines should be carried out in the region only with grapes harvested from the first semester, with a higher added value. In addition, grapes harvested in the second semester, mainly between October and December, should be used for young reds or sparkling wines, which are consumed more and are easily sold, being cheaper 
(A) Projection of the cases on the factor-plane $\left(\begin{array}{ll}1 \times & 2\end{array}\right)$ Cases with sum of cosine square $>=0,00$

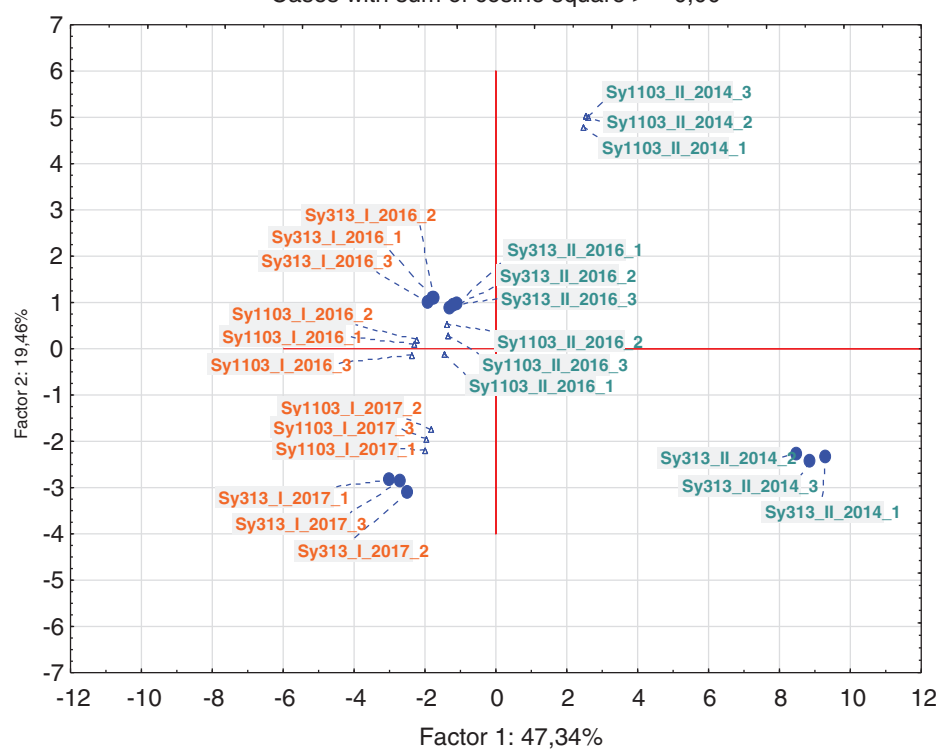

(B) Projection of the variables on the factor-plane $\left(\begin{array}{ll}1 \times & 2\end{array}\right)$ Active and Supplementary variables *Supplementary variable

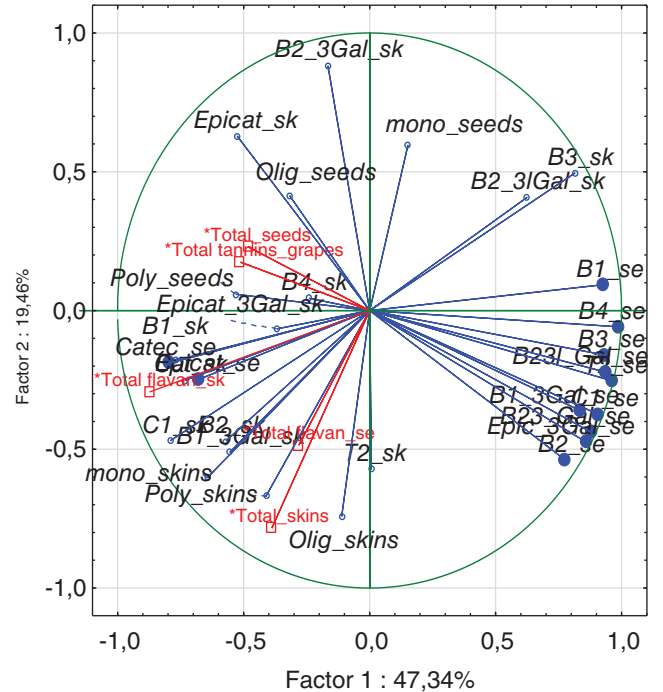

Figure 3. Principal component analysis of the fractionation for condensed tannins and small oligomeric flavanols in skins and seeds of Syrah (Vitis vinifera L.) grapes grown on two rootstocks and four harvest seasons in a tropical semiarid region of Brazil. All data are expressed as the average values of 3 replicates \pm standard deviation. Figure 3A, samples: Syrah 313_I, grapes from plants grafted onto IAC 313 during the first semester in the years of 2016 and 2017; Syrah 313_II, grapes from plants grafted onto IAC 313 during the second semester, in the years of 2014 and 2016; Syrah 1103_l, grapes from grapes of plants grafted onto 1103P during the first semester of 2016 and 2017; Syrah 1103_Il, grapes from plants grafted onto 1103P during the second semester in the years of 2014 and 2016; sk, skins; se, seeds. Figure 3B, compounds: mono, monomeric tannins; olig, oligomeric tannins; poly, polymeric tannins; Total skins, total condensed tannins in skins; Total_seeds, total condensed tannins in seeds; Cat, catechin; Epicat, epicatechin; epicat_3_Gal, epicatechin 3-O-gallate; B1, B2, B3, B4, procyanidin dimers; B1_3_Gal B1 3-O-gallate, B2_3_Gal B2 3-O-gallate, B2_31_Gal B2 3'-O-gallate, Procyanidin dimers gallate; $\mathrm{C} 1$ and $\mathrm{T} 2$, procyanidin trimers.

than aging wines. Subsequent studies should aim to evaluate the effect of season and rootstocks on the phenolic stability of the wines.

Future studies on viticulture practices in region are still needed; for example, canopy management (via green pruning) or productivity control per plant and hectare (between rootstocks and/or harvest seasons) can be adopted with the objective of maintaining or improving the quality of the grapes.

\section{ACKNOWLEDGEMENTS}

This research was supported by Brazilian companies: Coordenação de Aperfeiçoamento de Pessoal de Nível Superior (Capes - 6070/1302), Embrapa Grape \& Wine/Semi-Arid, CNPq project (403438/2013-6) and Rio Sol/Global Wines (Lagoa Grande, Pernambuco). In Portugal, we thank the research center in Instituto Superior de Agronomia: Linking Landscape, Environment, Agriculture and Food - LEAF (UID/AGR/04129/2013) and FCT for the scholarship of Egipto, R. (SFRH/BD/128847/2017).

\section{REFERENCES}

1 Camargo UA, Tonietto J, Hoffmann A. Progressos na viticultura brasileira. Revista Brasileira Fruticultura, Volume especial, 2011: E.:144-149.

2 International Organization of Grape and Wine (OIV). World vitiviniculture situation; 2017. Available from: http://www.oiv.int/public/ medias/5479/oiv-en-bilan-2017.pdf.

3 González-Neves G, Charamelo D, Balado J, Barreiro L, Bochicchio R, Gatto $\mathrm{G}$ et al., Phenolic potential of Tannat, Cabernet-Sauvignon and Merlot grapes and their correspondence with wine composition. Anal Chim Acta 513:191 - 196 (2004).
4 Pinkerton JN, Vasconcelos MC, Sampaio TL and Shaffer RG, Reaction of grape rootstocks to ring nematode "Mesocriconema xenoplax". Am J Enol Vitic 56:377-385 (2005).

5 Reynolds AG and Wardle DA, Rootstocks impact vine performance and fruit composition of grapes in British Columbia. Horttechnology 11:419-427 (2001).

6 Main G, Morris J and Striegler K, Rootstock effects on Chardonel productivity, fruit and wine composition. Am J Enol Vitic 53:37-40 (2002).

7 Soares JM and PCS L, A Vitivinicultura no Semiárido Brasileiro. Embrapa Informação Tecnológica, Brasília, Brasil (2009).

8 Reynolds AG, Managing wine quality. Viticulture and wine quality, vol I, Florida. CRC Press, USA (2010).

9 Tonietto J and Carbonneau A, A multicriteria climatic classification system for grape growing regions worldwide. Agric For Meteorol 124:81-97 (2004)

10 Sá BI, Sá IIS, Silva AS and Silva DF, Caracterização ambiental do Vale do Submédio São Francisco, in Subsídios técnicos para a indicação geográfica de procedência do Vale do Submédio São Francisco, Vol. 222. Embrapa Semiárido Documentos, Petrolina, pp. 9-16 (2009).

11 Carbonneau A,Champagnol F. Nouveaux systemes de culture integre Du vignoble. Programme, AIR-3-CT 93, 1993.

12 Bourzeix M, Weyland D and Heredia N, Étudedescatéchines et desprocyanidols de lagrappe de raisin, de vin et d'autresdérivés de lavigne. Bulletin OIV 59:1171-1254 (1986).

13 O.I.V, Recueildesmethodesinternacionales d'analysedesvins et desmoûts. Office Internacional de lavigne et duvin, Paris (2014).

14 Ribéreau-Gayon $P$, Le dosagedescomposésphénoliquestotauxdanslesvinsrouges. Anal Chim Acta 52:627-631 (1970).

15 Kramling TE and Singleton VL, An estimate of the non-flavonoid phenol in wines. Am J Enol Vitic 20:86-92 (1969).

16 Ribéreau-Gayon $\mathrm{P}$ and Stonestreet $\mathrm{E}$, Dosage des tannins du vin rouge et determination de leur structure. Anal Chim Acta 2:627-631 (1965).

17 De Freitas $V$ and Mateus N, Structural features of procyanidin interactions with salivary proteins. J Agric Food Chem 49:940-945 (2001).

18 Roggero JP, Coen S and Ragonnet B, High performance liquid chromatography survey on changes in pigment content in ripening 
grapes of Syrah. An approach to anthocyanin metabolism. Am J Enol Vitic 37:77-83 (1986).

19 Sun BS, Leandro MC, Ricardo-da-Silva JM and Spranger MI, Separation of grape and wine proanthocyanidins according to their degree of polymerisation. J Agric Food Chem 46:1390-1396 (1998).

20 Ricardo-da-Silva JM, Rosec JP, Bourzeix M and Heredia N, Separation and quantitative determination of grape and wine procyanidins by high-performance reversed-phase liquid chromatography. JSci Food Agric 53:85-92 (1990).

21 Labarbe B, Cheynier V, Brossaud F, Souquet JM and Moutounet M, Quantitative fractionation of grape proanthocyanidins according to their degree of polymerization. J Agric Food Chem 47:2719-2723 (1999).

22 Kennedy JA, Matthews MA and Waterhouse AL, Changes in grape seed polyphenols during fruit ripening. Phytochemistry 55:77-85 (2000).

23 Monagas $M$, Gómez-Cordovés C, Bartolomé B, Laureano $O$ and Ricardo-da-Silva JM, Monomeric, oligomeric and polimeric flavan-3-ol composition of wines and grapes from Vitis vinifera L. cv. Graciano, Tempranillo and Cabernet Sauvignon. J Agric Food Chem 51:6475-6481 (2003).

24 Sigler J, In den Zeiten des Klimawandels: Von der Süßreservezur Sauerreserve? Der Badische Winzer 33:21 - 25 (2008).

25 Oliveira JB, Faria DL, Duarte DF, Egipto R, Laureano O, Castro R et al., Effect of the harvest season on phenolic composition and oenological parameters of grapes and wines cv. Touriga Nacional'(Vitis vinifera I.) produced under tropical semi-arid climate, in the state of Pernambuco, Brazil. Cienc Tec Vitivinic 33:145-166 (2018).

26 Lima MS, Leite APS, Sampaio YC, Vianello F and Lima GPP, Influences of the Harvest Season on Analytical Characteristics of Syrah Grapes and Wines Produced in the Northeast Region of Brazil. Int J Agric For 5:151-159 (2015).

27 Leão PCS, Nunes BTG and Lima MAC, Canopy management effects on 'Syrah' grapevines under tropical semi-arid conditions. Sci Agr 73:209-216 (2016).

28 Ford CM, The Biochemistry of Organic Acids in the Grape. In The Biochemistry of the Grape Berry. Scopus, EBSCO, chapter 4, pp. 67-88 (2012).

29 Moreno J and Peinado R, Grape Acids. Enological Chemistry. Academic Press, Cambridge, MA (2012).
30 Costa E, Cosme F, Jordão AM and Mendes-Faia A, Anthocyanin profile and antioxidant activity from 24 grape varieties cultivated in two Portuguese wine regions. J Int Sci Vigne Vin 48:51-62 (2014).

31 Dalbó M and Feldberg N, Agronomic behavior of grape rootstocks resistant to young vine decline in Santa Catarina State, Brazil. BIO Web of Conferences 7, 39th World Congress of Vine and Wine, in Bento Gonçalves, Brazil. Vol. 01017, pp. 1-3 (2016).

32 Costa $E$, Cosme $F$ and Rivero-Pérez MD, Influence of wine region provenance on phenolic composition, antioxidant capacity and radical scavenger activity of traditional Portuguese red grape varieties. Eur Food Res Technol 241:61-73 (2015).

33 Ferrandino A and Guidoni S, Anthocyanins, flavonols and hydroxycinnamates: an attempt to use them to discriminate Vitis vinifera $\mathrm{L} . \mathrm{CV}$ 'Barbera' clones. Eur Food Res Technol 230:417-427 (2010).

34 Downey MO, Harvey JS and Robinson SP, Analysis of tannins in seeds and skins of Shiraz grapes throughout berry development. Aust J Grape Wine R 9:15-27 (2003).

35 Cosme F, Ricardo-da-Silva JM and Laureano O, Tannin profiles of Vitis vinifera L. CV. red grapes growing in Lisbon and from their monovarietal wines. Food Chem 112:197-204 (2009).

36 Texeira A, Eiras-Dias J, Castellarin SD and Gerós H, Berry phenolics of grapevine under challenging environments. Int J Mol Sci 14:18711-18739 (2013).

37 Bordiga M, Travaglia F, Locatelli M, Coisson JD and Arlorio M, Characterisation of polymeric skin and seeds proanthocyanidins during ripening in six Vitis vinifera L. cv. Food Chem 127:180-187 (2011).

38 Kyraleou M, Kallithraka S, Theodorou N, Teissedre $\mathrm{P}$, Kotseridis $\mathrm{Y}$ and Koundouras S, Changes in Tannin composition of Syrah grape skins and seeds during fruit ripening under contrasting water conditions. Molecules 22:1453 (2017).

39 Koyama K, Ikeda H, Poudel PR and Goto-Yamamoto N, Light quality affects flavonoid biosynthesis in young berries of Cabernet Sauvignon grape. Phytochemistry 78:54-64 (2012).

40 Barnuud NN, Mpelasoka F, Gibberd M and Bates B, Responses of grape berry anthocyanin and titratable acidity to the projected climate change across the Western Australian wine regions. Int J Biometeorol 58:1279-1293 (2014).

41 Leeuwen $C V$ and Darriet $P$, The impact of climate change on viticulture and wine quality. J Wine Econ 11:150-167 (2016). 